\title{
Salidroside reduces cold-induced mucin production by inhibiting TRPM8 activation
}

\author{
QI LI ${ }^{1}$, XIANG-DONG ZHOU ${ }^{1}$, VICTOR P. KOLOSOV ${ }^{2}$ and JULIY M. PERELMAN ${ }^{2}$ \\ ${ }^{1}$ Department of Respiratory Medicine, Second Affiliated Hospital, Chongqing Medical University, Chongqing 400010, \\ P.R. China; ${ }^{2}$ Far Eastern Scientific Center of Physiology and Pathology of Respiration, Siberian Branch, \\ Russian Academy of Medical Sciences, Blagoveschensk 675000, Russia
}

Received April 18,2013; Accepted June 28, 2013

DOI: $10.3892 /$ ijmm.2013.1434

\begin{abstract}
Salidroside is an effective component of the traditional Chinese herb, Rhodiola rosea, that is known to have the ability to protect individuals from cold attacks. In the present study, we investigated the effects of salidroside on respiratory epithelial cells exposed to cold temperatures. We wished to determine whether salidroside exerts any effect on cold-induced mucin (MUC) production and the possible mechanisms involved in this process. We incubated HBE16 cells with salidroside, exposed them to a cold stimulus $\left(18^{\circ} \mathrm{C}\right)$, and assayed the following endpoints: MUC production (the expression of MUC5AC), concentration intracellular of free calcium $\left(\left[\mathrm{Ca}^{2+}\right] \mathrm{i}\right)$, the activation of the transient receptor potential melastatin 8 (TRPM8) channel and the cAMP response element-binding protein (CREB). Our results revealed a significant increase in the $\left[\mathrm{Ca}^{2+}\right]$ i concentration, as well as in TRPM8 and CREB expression in the cold-stimulated cells. MUC5AC expression was also increased. Treatment of the cells with salidroside at concentrations of 50 and $100 \mu \mathrm{M}$ decreased the $\left[\mathrm{Ca}^{2+}\right]$ i concentration, with a maximal effect detected in the cells treated with $100 \mu \mathrm{M}$ salidroside. The expression of TRPM8 and TRPM8 channel conductivity were also repressed by salidroside; salidroside decreased the high levels of CREB activity and phosphorylation observed in the cold-stimulated cells. Furthermore, we transfected the cold-stimulated cells with CREB small interfering RNA (siRNA) to analyze TRPM8
\end{abstract}

Correspondence to: Professor Xiang-Dong Zhou, Department of Respiratory Medicine, Second Affiliated Hospital, Chongqing Medical University, No. 74 Linjiang Road, Chongqing 400010, P.R. China

E-mail: zxd999@263.net

Abbreviations: TRPM8, transient receptor potential melastatin 8; CRE, cAMP response element; ELISA, enzyme-linked immunosorbent assay; HRP, horseradish peroxidase; MUC, mucin; siRNA, small interfering RNA

Key words: salidroside, mucin, airway, cold stimuli, transient receptor potential melastatin 8 gene expression in the absence of CREB activity. The results revealed that the cells treated with either CREB siRNA or salidroside expressed low levels of TRPM8 mRNA and protein. These results indicate that salidroside reduces MUC overproduction induced by cold stimuli and that salidroside exerts its protective effects by inhibiting TRPM8 activation, mainly by decreasing CREB activity.

\section{Introduction}

Cold stimuli are known to exacerbate chronic obstructive pulmonary disease (COPD) and have been shown to promote mucin (MUC) hypersecretion (1). Excessive MUC production leads to airway obstruction and enhances inflammation. Previous studies have mainly focused on secondary inflammatory processes (2) and bacterial (3) or viral infections $(4,5)$ that occur in the airways following exposure to cold temperatures; however, the molecular mechanisms behind cold-induced mucus secretion have not yet been fully elucidated. Human organs express ion channels of the transient receptor potential (TRP) family, including some ion channels that respond at distinct temperature thresholds (6-9). TRP melastatin 8 (TRPM8) is a member of this family that is activated by temperatures ranging from 8 to $25^{\circ} \mathrm{C}$. TRPM8 is a ligand-gated cation channel with moderate to high selectivity for calcium ions $(10,11)$.

TRPM8 can be activated by cold temperatures and by cooling agents, such as menthol, eucalyptol and icilin. In a previous study, we found that TRPM8 plays a critical role in cold-induced MUC secretion in the human respiratory system (12). Human airway epithelial cells exposed to cold temperatures exhibited activated TRPM8 channels, and MUC5AC expression was upregulated through the TRPM8-Ca ${ }^{2+}$-phospholipase C (PLC)-phosphatidylinositol bisphosphate (PIP2) pathway. Thus, we hypothesized that TRPM8 plays a role in cold-induced MUC secretion. In this study, we aimed to discover methods of inhibiting cold-induced MUC hypersecretion.

Salidroside (rhodioside) is a glycoside compound primarily found in the plant, Rhodiola rosea, which grows in cold, high-latitude areas. It is well known that salidroside has pharmacological effects on many pathological conditions, including radiation poisoning (13), inflammation (14), fatigue, 
aging and hypoxia $(15,16)$. Other studies have found that salidroside exerts its protective effects mainly by repressing the inflow of intracellular free calcium $\left(\mathrm{Ca}^{2+}\right)\left(\left[\mathrm{Ca}^{2+}\right] \mathrm{i}\right)$ into cells. Considering what is already known about salidroside and TRPM8, we hypothesized that salidroside has the ability to protect cells from cold nociceptive stimuli and that it may play a positive role in the airway system. In the present study, we explored the regulation of TRPM8 gene transcription in cold-assaulted cells and examined the effects of salidroside on TRPM8 channels and MUC production. We used the HBE16 human airway epithelial cell line for in vitro studies. The cells were pre-treated with salidroside and exposed to cold temperatures; the protein and mRNA levels of MUC5AC were then determined. The expression levels of TRPM8 and the transcription factor, cAMP response element-binding protein (CREB), were assayed to investigate whether there were any differences in the levels of these factors following treatment with salidroside. Furthermore, we transfected the cells with CREB small interfering RNA (siRNA) to determine whether the transcription factor, CREB, is involved in TRPM8 gene transcription.

\section{Materials and methods}

Reagents. Dulbecco's modified Eagle's medium (DMEM)/ Ham's F12 medium, HEPES, fetal bovine serum (FBS), anti- $\beta$-actin monoclonal antibody, salidroside ( $>98 \%$ purity; National Institute for Food and Drug Control),CREB siRNA and negative control siRNA were purchased from Sigma-Aldrich (St. Louis, MO, USA). Lipofectamine ${ }^{\circledR} 2000$ and OPTI-MEM Reduced Serum Medium were purchased from Invitrogen (San Diego, CA, USA). The rabbit anti-TRPM8 polyclonal antibody was purchased from Abcam (Cambridge, MA, USA) and the horseradish peroxidase (HRP)-goat anti-rabbit IgG antibody was purchased from Santa Cruz Biotechnology, Inc. (Santa Cruz, CA, USA). CREB-Luc reporter constructs were purchased from Biocat (Catalonia, Spain). The Dual Luciferase Reporter Gene Assay kit was purchased from BioTime Technology (Beijing, China). The pRL-TK Renilla Luciferase Reporter Vector was purchased from Promega (Madison, WI, USA). The high-purity total RNA extraction kit was purchased from Bioteke Biotechnology (Beijing, China). The PrimeScript RT Reagent kit was purchased from Takara (Dalian, China).

Cell culture. HBE16 human airway epithelial cells were plated in 6-well plates at a concentration of 5-6x $10^{5}$ cells/well in $2 \mathrm{ml} \mathrm{DMEM} / \mathrm{Ham}^{\mathrm{s}} \mathrm{F} 12$ medium that contained $10 \% \mathrm{FBS}$. The cells were then incubated at $37^{\circ} \mathrm{C}$ and $5 \% \mathrm{CO}_{2}$. The culture medium was changed to growth factor-free medium prior to the start of each experiment. Cell supernatants and lysates were collected and assays were performed, as described below.

Cell viability measurements. Confluent HBE16 cells were incubated with $10,50,100$, or $200 \mu \mathrm{M}$ salidroside for $24 \mathrm{~h}$. We used the 3-(4,5-dimethylthiazol-2-yl)-2,5-diphenyltetrazolium bromide (MTT) reduction method to detect cell viability and to select the appropriate dose of salidroside for the subsequent experiments.
siRNA transfection. Cells were plated at a density of $1-2 \times 10^{6}$ cells $/ \mathrm{ml}$ and incubated at $37^{\circ} \mathrm{C}$ until the cells were $60-80 \%$ confluent. CREB siRNA $(0.5 \mu \mathrm{g})$ were diluted in $100 \mu \mathrm{l}$ of siRNA transfection medium (solution A); $6 \mu \mathrm{l}$ siRNA transfection reagent was diluted in $100 \mu \mathrm{l}$ of siRNA transfection medium (solution $\mathrm{B})$. The solutions $(\mathrm{A}+\mathrm{B})$ were subsequently mixed gently and incubated at room temperature for $45 \mathrm{~min}$. The cells were washed once with $2 \mathrm{ml}$ of siRNA transfection medium followed by the addition of $0.8 \mathrm{ml}$ of the siRNA transfection reagent mixture (solutions $\mathrm{A}+\mathrm{B}$ ). The cells were then incubated for $7 \mathrm{~h}$ at $37^{\circ} \mathrm{C}$ in a $\mathrm{CO}_{2}$ incubator and were recovered in $2 \mathrm{ml}$ of DMEM/Ham's F12 medium containing 10\% FBS for an additional $24 \mathrm{~h}$. The medium was then aspirated and replaced with fresh growth medium for the following assays (see below for details).

RNA isolation and real-time PCR for MUC5AC and TRPM8 $m R N A$. After the HBE16 cells were harvested, total RNA was extracted from the cells using the Bioteke high-purity total RNA extraction kit, and RNA integrity was verified using $1.5 \%$ agarose gel electrophoresis. The absorbance at $260 / 280 \mathrm{~nm}$ $\left(\mathrm{A}_{260 / 280}\right)$ was in the range of 1.8-2.0. Total RNA was primed with an oligo(dT) primer and reverse transcribed using the PrimeScript RT Reagent kit. Real-time PCR was performed using the SYBR Premix EX Taq ${ }^{\mathrm{TM}}$ II real-time PCR kit. The sequences of the primers used for real-time PCR were as follows: MUC5AC (U06711) forward, 5'-CAGCCACGTCCCC TTCAATA-3' and reverse, 5'-ACCGCATTTGGGCATCC-3'; TRPM8 (NM024080) forward, 5'-ACTCAGAAGGCTGAGG TACA-3' and reverse, 5'-TTCAGTCGGAGTCTCACTCT-3'; and GAPDH (BC026907) forward, 5'-GAAGGTGAAGGT CGGAGT-3' and reverse, 5'-GAAGATGGTGATGGGA TTTC-3'. GAPDH was used as the loading control. Relative mRNA expression was determined by comparing it to a standard curve.

Enzyme-linked immunosorbent assay (ELISA) for MUC5AC protein. MUC5AC protein levels in the cell lysates and supernatants were measured using ELISA. Cell lysates at multiple dilutions were prepared with phosphate-buffered saline (PBS). Cell culture supernatants were collected for this assay. In addition, $50 \mu 1$ of each sample were incubated with bicarbonate-carbonate buffer $(50 \mu \mathrm{l})$ at $40^{\circ} \mathrm{C}$ in a $96-$-well plate until dry. The wells were washed 3 times with PBS and blocked with $2 \%$ bovine serum albumin (BSA) for $1 \mathrm{~h}$ at room temperature. The wells were then incubated with mouse antihuman MUC5AC monoclonal antibody (45M1) $(10 \mu \mathrm{g} / \mathrm{ml}$; Neomarkers Inc., Fremont, CA, USA) diluted in PBS containing $0.05 \%$ Tween-20 for $1 \mathrm{~h}$ at room temperature. After washing 3 times, the wells were incubated with HRP-conjugated goat anti-mouse $\operatorname{IgG}(1 \mu \mathrm{g} / \mathrm{ml})$ for $1 \mathrm{~h}$. HRP was developed with $3,3^{\prime}, 5,5^{\prime}$-tetramethylbenzidine (TMB) peroxidase solution, quenched with $1 \mathrm{M} \mathrm{H}_{2} \mathrm{SO}_{4}$ and the absorbance at $450 \mathrm{~nm}$ was measured.

Western blot analysis for TRPM8 and phosphorylated CREB ( $p$-CREB) protein levels. Total protein was determined by BCA analysis. The cells were lysed in lysate buffer, disrupted on ice for $20 \mathrm{~min}$, and then centrifuged at $12,000 \mathrm{rpm}$ for $15 \mathrm{~min}$ at $4^{\circ} \mathrm{C}$ to remove the nuclei and unbroken cells. The 
total protein concentration in the cell lysates was determined by BCA assay. Equal amounts of protein were diluted in SDS sample buffer and boiled for $5 \mathrm{~min}$. Proteins were resolved on $6 \%$ SDS gels. After running, the gels were equilibrated in transfer buffer containing $25 \mathrm{mM}$ Tris- $\mathrm{HCl}, 192 \mathrm{mM}$ glycine and $20 \%$ methanol ( $\mathrm{pH} 8.3$ ). The proteins were then transferred by electrophoresis onto polyvinylidene difluoride (PVDF) membranes. The membranes were incubated in $5 \%$ milk dissolved in PBS and $0.05 \%$ Tween-20 for $1 \mathrm{~h}$ at room temperature and subsequently incubated with rabbit anti-TRPM8 (diluted 1:200) or rabbit anti-p-CREB (Ser-129) polyclonal antibodies (diluted 1:500) overnight at $4^{\circ} \mathrm{C}$. After washing 3 times, the membranes were incubated with an HRP-labeled goat anti-rabbit IgG antibody (diluted 1:1,000) for $2 \mathrm{~h}$ at room temperature. Enhanced chemiluminescence (ECL) and autoradiography were performed to visualize TRPM8 and p-CREB protein. The membranes were also blotted for $\beta$-actin and $\alpha$-tubulin to ensure equal protein loading.

Immunofluorescence for TRPM8. Cells were fixed with $4 \%$ paraformaldehyde and subsequently permeabilized with $0.1 \%$ Triton X-100 in PBS for 30 min. The cells were rinsed, blocked in $1 \%$ BSA plus $1 \%$ normal goat serum and incubated with rabbit anti-TRPM8 (diluted 1:500) overnight at $4^{\circ} \mathrm{C}$. After 3 washes of 10 min each in $0.1 \%$ Triton X-100/PBS, the cells were incubated with FITC-conjugated fluorescent goat anti-rabbit $\operatorname{IgG}(1: 500)$ for $2 \mathrm{~h}$ at room temperature followed by cellular nuclear staining with 4'6-diamidino-2-phenylindole (DAPI). The samples were examined using a Leica inverted TCS-SP2 confocal microscope that was equipped with appropriate fluorescence filters.

Determination of TRPM8 channel conductivity. Whole-cell patch-clamp experiments were performed using an EPC-10 amplifier and IGOR Pro 4.0 software for data acquisition and analysis. Frequencies of $10 \mathrm{KHz}$ were selected for sampling and $2 \mathrm{KHz}$ for filtration. The extracellular solution used for electrophysiological recordings consisted of $140 \mathrm{mM} \mathrm{NaCl}$,

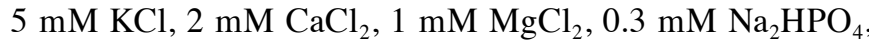
$0.4 \mathrm{mM} \mathrm{KH}_{2} \mathrm{PO}_{4}, 4 \mathrm{mM} \mathrm{NaHCO}, 5 \mathrm{mM}$ glucose and $10 \mathrm{mM}$ HEPES (the $\mathrm{pH}$ was adjusted to 7.4 using $\mathrm{NaOH}$ ). The intracellular solution filled into patch-clamp pipettes contained $140 \mathrm{mM} \mathrm{KCl}, 1 \mathrm{mM} \mathrm{MgCl} 2,2.5 \mathrm{mM} \mathrm{CaCl}_{2}, 4 \mathrm{mM}$ EGTA and $10 \mathrm{mM}$ HEPES. The calculated free $\mathrm{Ca}^{2+}$ concentration in this solution was $150 \mathrm{nM}$, and the $\mathrm{pH}$ was adjusted to $7.2 \mathrm{using}$ $\mathrm{KOH}$ as previously described (17). The borosilicate glass patch pipettes used for the whole-cell recordings had resistances of 2-4 $M \Omega$ when filled with intracellular solutions.

$\mathrm{Ca}^{2+}$ influx detection. The cells were exposed to cold temperatures $\left(18^{\circ} \mathrm{C}\right)$ or pre-treated with salidroside and collected at different time intervals. We resuspended the cells in D-Hanks buffer containing $0.2 \% \mathrm{FBS}\left(10^{6}\right.$ cells $\left./ \mathrm{ml}\right)$, removed $1 \mathrm{ml}$ of the cell suspension to an Eppendorf tube and then added $2 \mu 1$ Fura-2/AM stock solution to the cells followed by incubation with shaking at $37^{\circ} \mathrm{C}$ for $60 \mathrm{~min}$. The cells were centrifuged at 1,300 rpm for $6 \mathrm{~min}$, washed twice with pre-heated D-Hanks buffer containing $0.2 \%$ BSA and resuspended in D-Hanks buffer. The fluorescence intensity was then observed using a dual wavelength spectrophotometer (Hitachi F-3000).
The 340/380 nm fluorescence intensity ratio of each sample is abbreviated as $\mathrm{R}$. The $380 \mathrm{~nm}$ fluorescence intensity of Fura-2 under $\mathrm{CA}^{2+}$-free and $\mathrm{Ca}^{2+}$ saturation conditions are abbreviated as Fmin and Fmax, respectively. As the controls, $40 \mu 12.5 \%$ Triton $\mathrm{X}-100$ were added to the cells to detect the maximum fluorescence intensity ratio ( $\mathrm{Rmax}$ ) and $40 \mu \mathrm{l}$ $250 \mathrm{mM} \mathrm{Ca}^{2+}$ chelator EGTA were added to the cells to detect the minimum fluorescence intensity ratio ( $\mathrm{Rmin}$ ). The $\left[\mathrm{Ca}^{2+}\right]$ i concentrations were calculated using the formula $\left[\mathrm{Ca}^{2+}\right]$ $\mathrm{i}=\mathrm{Kd}[(\mathrm{R}-\mathrm{Rmin}) /(\mathrm{R} \max -\mathrm{R})](\mathrm{Fmin} / \mathrm{Fmax})$.

CREB activity assay. CREB activity was determined using the CREB-Luciferase Reporter Assay System (Biocat). The CREB-Luc and pRL-TK Renilla Luciferase Reporter plasmids were transfected into the HBE16 cells using Lipofectamine ${ }^{\circledR} 2000$. Eighteen hours after transfection, the cells were pre-incubated with $100 \mu \mathrm{M}$ salidroside for $30 \mathrm{~min}$ and exposed to cold temperatures $\left(18^{\circ} \mathrm{C}\right)$. CREB activity was assayed in accordance with the manufacturer's instructions provided with the Luciferase Reporter Gene Assay kit. The results were expressed as detected luciferase relative light units (RLU)/Renilla luciferase RLU.

Statistical analysis. Data analysis was performed using the SPSS 17.0 statistical software package (SPSS, Inc., Chicago, IL, USA). All in vitro experiments using cell lines included samples from at least 6 separate wells and 2-3 independent experiments. Comparisons of $>2$ groups were made using the Student's t-test or a one-way analysis of variance (ANOVA) followed by Bonferroni's analysis. A P-value $<0.05$ was considered to indicate a statistically significant difference.

\section{Results}

Viability of HBE16 cells following exposure to salidroside. The cells were incubated with $10,50,100$, or $200 \mu \mathrm{M}$ salidroside for various periods of time to determine cellular proliferation rates following exposure to salidroside. Salidroside at a concentration of $200 \mu \mathrm{M}$ inhibited cell proliferation after $16 \mathrm{~h}$. Following incubation with 10,50 , or $100 \mu \mathrm{M}$ salidroside for $24 \mathrm{~h}$, the viability of these cells did not differ significantly from that of the non-treated cells (Fig. 1). These results indicate that lower doses of salidroside do not affect cell viability. Therefore, we selected to use the concentrations of 50 and $100 \mu \mathrm{M}$ for the following experiments.

Salidroside decreases cold-induced MUC5AC expression. To investigate the effects of cold temperatures on MUC5AC expression in airway epithelial cells, we exposed the HBE16 cells to cold temperatures $\left(18^{\circ} \mathrm{C}\right)$ for various periods of time. MUC5AC mRNA levels were upregulated after $1 \mathrm{~h}$ of exposure to cold temperatures, with the concentration of MUC5AC protein in the cell lysates and culture supernatants increasing as well. The mRNA and protein levels of MUC5AC continued to increase, reaching a plateau at $8 \mathrm{~h}$. These results indicate that exposure to cold temperatures actively induces MUC5AC expression. The cells were then incubated with $50 \mu \mathrm{M}$ salidroside prior to exposure cold temperatures. The MUC5AC protein and mRNA levels in the salidroside-treated cells were lower than those observed in the cold-stimulated group at $6 \mathrm{~h}$. 


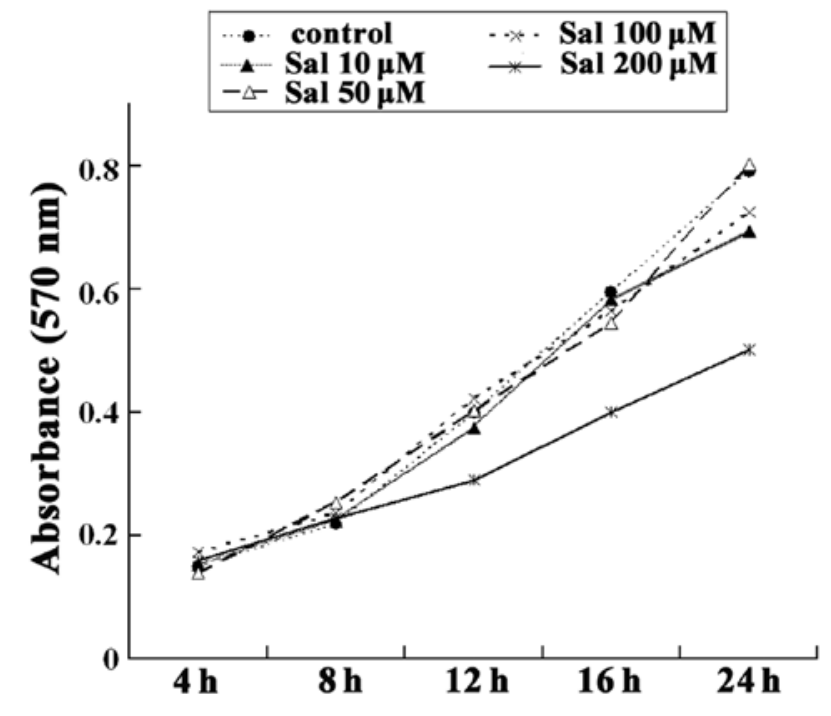

Figure 1 . The viability of the HBE16 cells was not affected by $100 \mu \mathrm{M}$ salidroside. HBE16 cells were incubated with various concentrations of salidroside and the growth rates of the cells in each group were measured by MTT assay at 4, 6, 8, 12, 16 and $24 \mathrm{~h}$ of incubation. Sal, salidroside.

Treatment of the cells with $100 \mu \mathrm{M}$ salidroside for $8 \mathrm{~h}$ significantly attenuated the cold-induced intracellular synthesis and secretion of the MUC5AC protein (Fig. 2), indicating that salidroside time- and dose-dependently reduced MUC5AC expression induced by cold stimulation.

Salidroside decreases $I_{\text {TRPMS }}$ membrane currents. In a previous study, we found that cold temperatures induce TRPM8 activation (12). We further assayed the activation of TRPM8 in cold-stimulated HBE16 cells by patch-clamping the cells at various time points following exposrue to cold temperatures. The current density of cold-stimulated TRPM8 channels increased at $15 \mathrm{sec}$ and reached a plateau at $6 \mathrm{~min}$. In the salidroside-treated cells, TRPM8 activation began to decrease after $40 \mathrm{sec}$. Salidroside significantly decreased the current through cold-stimulated TRPM8 channels at $10 \mathrm{~min}$ of recording in comparison with the untreated cold-stimulated channels $(\mathrm{P}<0.05)$. The $100 \mu \mathrm{M}$ concentration of salidroside was more effective at reducing currents than the $50 \mu \mathrm{M}$ concentration, showing maximal effects at 20 min (Fig. 3). These results indicate that TRPM8 activation is involved in cold-stimulated MUC expression and that salidroside inhibits currents through TRPM8, suggesting a previously unknown property of salidroside.

Salidroside reduces cold-induced TRPM8 expression in HBE16 cells. To further confirm the inhibitory effects of salidroside on TRPM8, we investigated the mRNA and protein expression of TRPM8 following incubation with salidroside. The cells were pre-treated with salidroside and then exposed to cold temperatures $\left(18^{\circ} \mathrm{C}\right)$. The TRPM8 mRNA and protein levels were then detected by real-time PCR, western blot analysis and immunofluorescence assay, respectively. The cells were exposed to cold temperatures $\left(18^{\circ} \mathrm{C}\right)$ for $6 \mathrm{~h}$; exposure to cold temperatures significantly increased TRPM8 protein and mRNA levels compared with the normal control group $(\mathrm{P}<0.05)$, and the cellular TRPM8 levels continued to increase
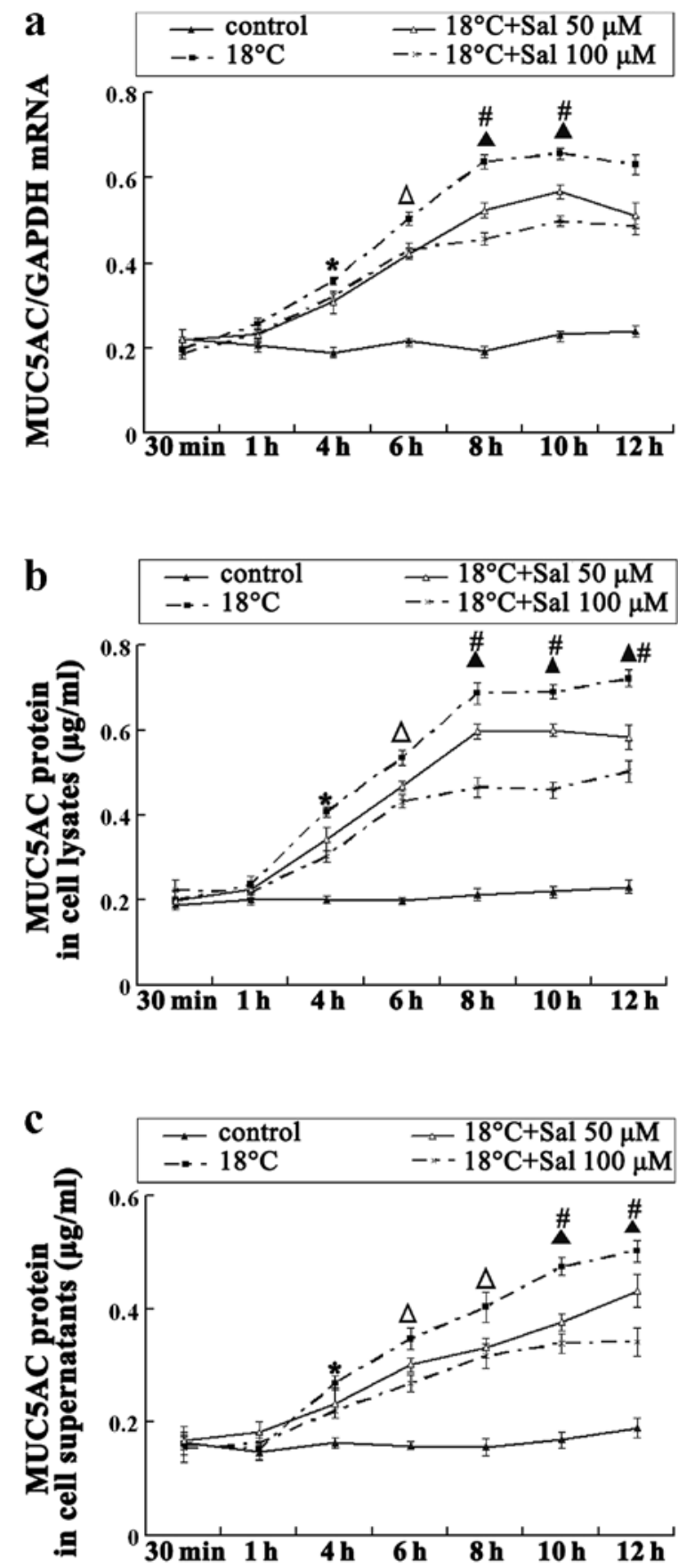

Figure 2. Salidroside downregulates cold-induced MUC5AC expression (a) Cells were treated with various concentrations of salidroside (50 or $100 \mu \mathrm{M}$ ) prior to exposure to cold temperatures. The MUC5AC mRNA levels in each group were detected by real-time PCR at various time points $(1,4,6$, $8,10,12 \mathrm{~h}$ ) as described in Materials and methods. The data shown are the means \pm SD from 6 different samples. (b) MUC5AC protein levels in cell lysates. Cells were treated with salidroside or exposed to cold temperatures $\left(18^{\circ} \mathrm{C}\right)$ as described in (a) and subsequently harvested, lysed and analyzed by ELISA. (c) MUC5AC protein levels in cell supernatants. Cells were treated as described in (a) and cell supernatants were collected and tested for MUC5AC protein levels by ELISA. " $\mathrm{P}<0.05$ compared with the control group; ${ }^{\triangle} \mathrm{P}<0.01$ compared with the control group; ${ }^{\wedge} \mathrm{P}<0.05$ compared with the $50 \mu \mathrm{M}$ salidroside-treated group; ${ }^{\prime} \mathrm{P}<0.01$ compared with the $100 \mu \mathrm{M}$ salidroside-treated group. P-values were calculated using the paired Student's $\mathrm{t}$-test. Sal, salidroside.

in a time-dependent manner. The cells pre-treated with salidroside prior to exposure to cold temperatures had lower 


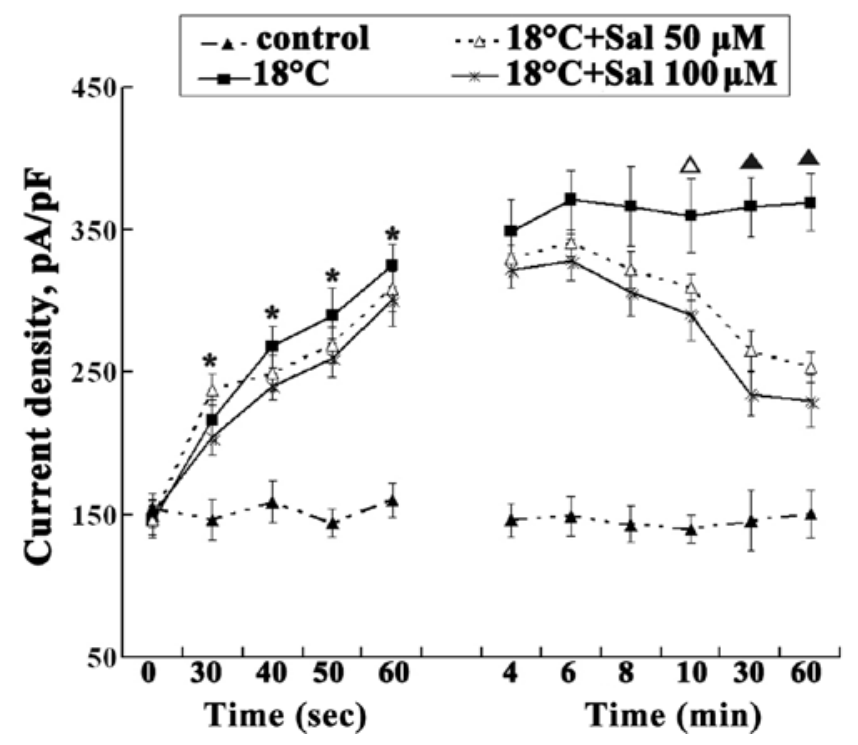

Figure 3. Salidroside inhibits cold-induced membrane currents through transient receptor potential melastatin 8 (TRPM8) channels in HBE16 cells. Cells were pre-incubated with salidroside (50 and $100 \mu \mathrm{M})$ and then exposed to cold temperatures $\left(18^{\circ} \mathrm{C}\right)$. The TRPM8 currents at various time points following exposure to cold temperatures were determined by a patch clamp. ${ }^{*} \mathrm{P}<0.05$ compared with the control group; ${ }^{\wedge} \mathrm{P}<0.05$ compared with the $100 \mu \mathrm{M}$ salidroside-treated group; ${ }^{\wedge} \mathrm{P}<0.01$ compared with the $100 \mu \mathrm{M}$ salidroside-treated group. P-values were calculated using the paired Student's t-test. Sal, salidroside.

TRPM8 expression levels than the non-treated cells $(\mathrm{P}<0.05)$. The high dose of salidroside $(100 \mu \mathrm{M})$ showed more potent inhibitory effects on increased TRPM8 expression than the low dose $(50 \mu \mathrm{M})$ (Figs. 4 and 5). These results indicate that salidroside represses TRPM8 not only by reducing TRPM8 activation but also by inhibiting TRPM8 mRNA and protein expression.

Salidroside inhibits $\left[\mathrm{Ca}^{2+}\right] \mathrm{i}$ in $\mathrm{HBE} 16$ cells. To investigate the mechanisms underlying the salidroside-mediated TRPM8 inhibition, we assayed the free calcium influx in the cells, which is crucial to TRPM8 activation and is known to play a role in many other salidroside-mediated protective events. The HBE16 cells were loaded with Fura-2/AM to examine the intracellular calcium concentration. When the HBE16 cells were exposed to cold temperatures $\left(18^{\circ} \mathrm{C}\right)$, we observed that the $\left[\mathrm{Ca}^{2+}\right]$ i concentration began to increase after $4 \mathrm{~min}$ and continued to increase, reaching a plateau at $10 \mathrm{~min}$, compared with the normal group $(\mathrm{P}<0.01)$. In the HBE16 cells incubated with salidroside prior to exposure to cold temperatures, the increase in the $\left[\mathrm{Ca}^{2+}\right] \mathrm{i}$ concentration was significantly attenuated at $8 \mathrm{~min}$. Furthermore, pre-treatment of the cells with both concentrations of salidroside $(50$ and $100 \mu \mathrm{M})$ decreased the $\left[\mathrm{Ca}^{2+}\right]$ i concentration in a dose-dependent manner (Fig. 6).

Salidroside decreases TRPM8 expression by inhibiting CREB activity in HBE16 cells. Previous studies have reported that the TRPM8 promoter may have a CREB binding site (18). To determine whether CREB is involved in TRPM8 activation, we first assayed the expression and activity of CREB in the cells under cold assault, and then transfected the cells with CREB siRNA to investigate the effects of CREB on TRPM8 a
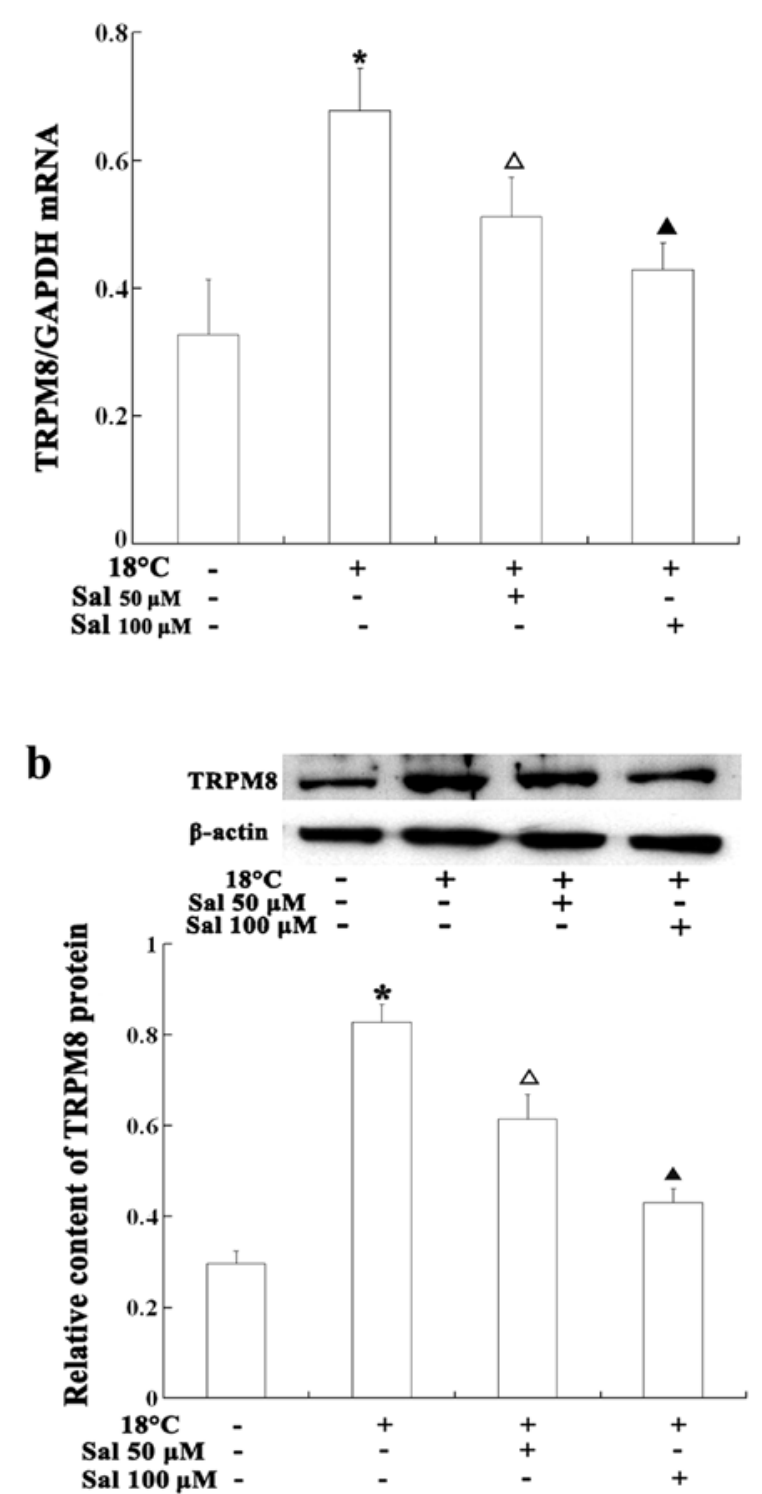

Figure 4. Salidroside decreases transient receptor potential melastatin 8 (TRPM8) expression in cold-stimulated cells. HBE16 cells were treated with 2 different concentrations of salidroside (50 and $100 \mu \mathrm{M}$ ) for $6 \mathrm{~h}$. (a) The level of TRPM8 mRNA in the HBE16 cells following treatment with salidroside was detected by real-time PCR. (b) The level of TRPM8 protein in the HBE16 cells following treatment with salidroside was determined by western blot analysis. TRPM8 expression levels were determined using densitometry analysis. Protein levels were calculated as the ratio of TRPM8 to $\beta$-actin and normalized to the control. Data shown are the means \pm SD from 6 different samples. ${ }^{*} \mathrm{P}<0.05$ compared with the control group; ${ }^{\wedge} \mathrm{P}<0.01$ compared with the cold-stimulated $\left(18^{\circ} \mathrm{C}\right)$ group; ${ }^{\wedge} \mathrm{P}<0.05$ compared with the cold-stimulated $\left(18^{\circ} \mathrm{C}\right)$ group. P-values were calculated using the paired Student's t-test. Sal, salidroside.

expression. Following the incubation of the HBE16 cells under cold conditions for $6 \mathrm{~h}$, the mRNA and protein levels of TRPM8 increased when compared with the control cells kept at warm temperatures. When the cells were transfected with CREB siRNA prior to exposure to cold temperatures $\left(18^{\circ} \mathrm{C}\right)$, the TRPM8 mRNA and protein levels were considerably lower than the levels observed in the non-transfected cells 

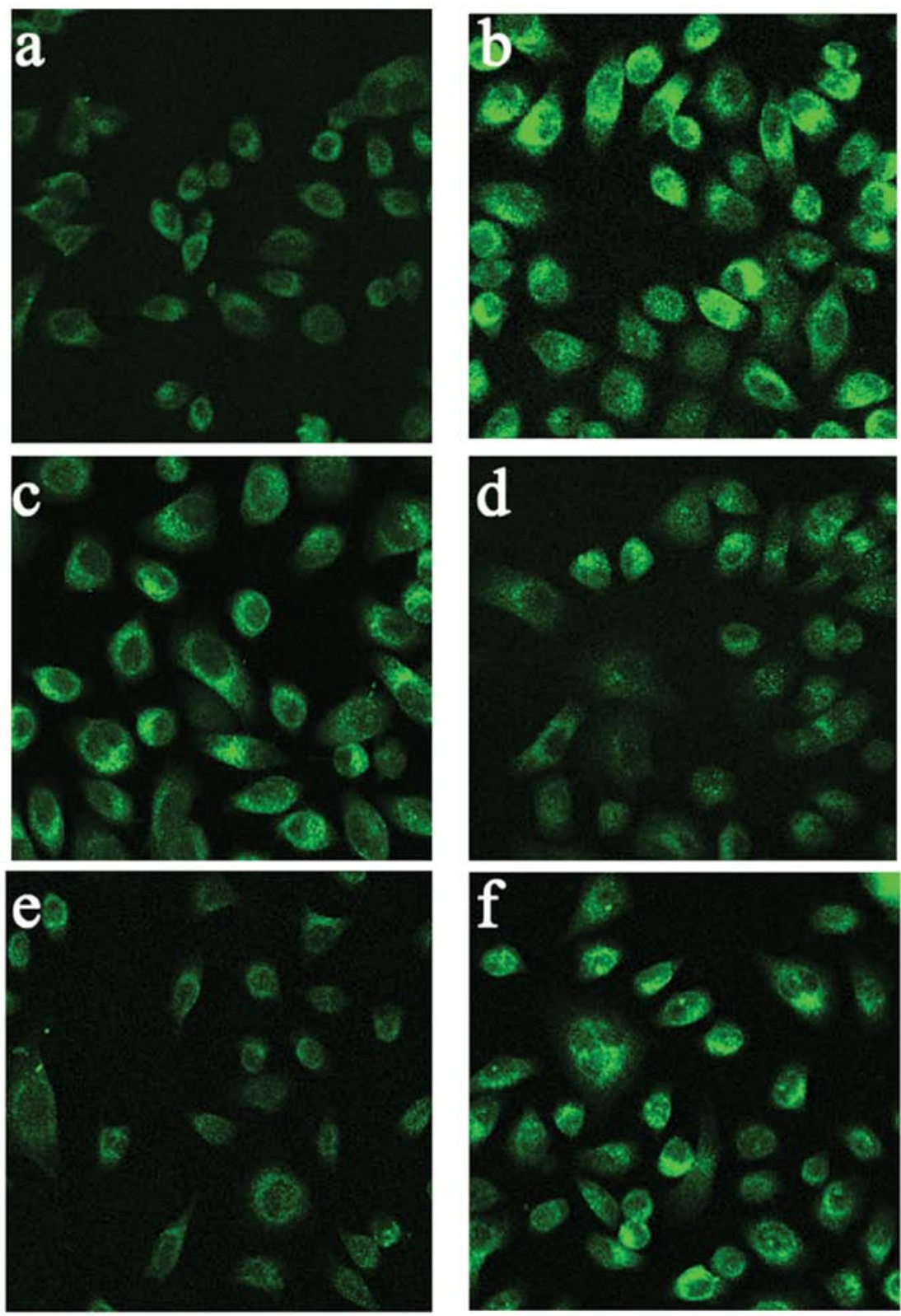

Figure 5. Salidroside and cAMP response element-binding protein (CREB) small interfering RNA (siRNA) decrease the expression of transient receptor potential melastatin 8 (TRPM8) protein in HBE16 cells. HBE16 cells were treated with 2 different concentrations of salidroside $(50$ and $100 \mu \mathrm{M})$ or transfetced with CREB siRNA. The protein expression was assayed by immunofluorescence. (a) Untreated HBE16 cells; (b) cold-stimulated (18 $\left.{ }^{\circ} \mathrm{C}\right)$ group; (c) coldstimulated $\left(18^{\circ} \mathrm{C}\right)+50 \mu \mathrm{M}$ salidroside-treated group; (d) cold-stimulated $\left(18^{\circ} \mathrm{C}\right)+100 \mu \mathrm{M}$ salidroside-treated group; (e) cold-stimulated $\left(18^{\circ} \mathrm{C}\right)+\mathrm{CREB}$ siRNA-transfected group; (f) cold-stimulated $\left(18^{\circ} \mathrm{C}\right)+$ control siRNA-transfected group. The samples were run in triplicate and in 3 separate experiments. Data are expressed as the means $\pm \mathrm{SE}, \mathrm{n}=6$.

(Figs. 5 and 7). Exposure to cold temperatures also increased the levels of p-CREB. The cells transfected with CREB siRNA showed lower levels of p-CREB, an effect similar to the one observed in the salidroside-treated cells $(\mathrm{P}<0.05$ compared with the cold-stimulated $\left(18^{\circ} \mathrm{C}\right)$ cells (Fig. $\left.8 \mathrm{~A}\right)$. We additionally transfected the cells with a CREB-Luc Reporter plasmid to measure the activity of CREB in the cold-stimulated cells. The cells exposed to cold temperatures $\left(18^{\circ} \mathrm{C}\right)$ showed higher RLU levels than the normal control cells, while the cells incubated with salidroside prior to exposure to cold temperatures exhibited lower RLU levels than the cold-stimulated cells not treated with salidroside $(\mathrm{P}<0.01)$ (Fig. 8B). These results suggest that CREB plays an important role in TRPM8 gene transcription and that salidroside represses TRPM8 expression by inhibiting CREB activity.

\section{Discussion}

Mucus overproduction is a clinical hallmark of acute exacerbation of COPD. One of the important aggravating factors is exposure to cold temperatures, which can cause mucociliary dysfunction and the accumulation of inflammatory factors, which may ultimately result in a bacterial infection in the respiratory system. The effective management of COPD exacerbation requires a thorough understanding of the underlying pathophysiological mechanisms that shape its clinical manifes- 


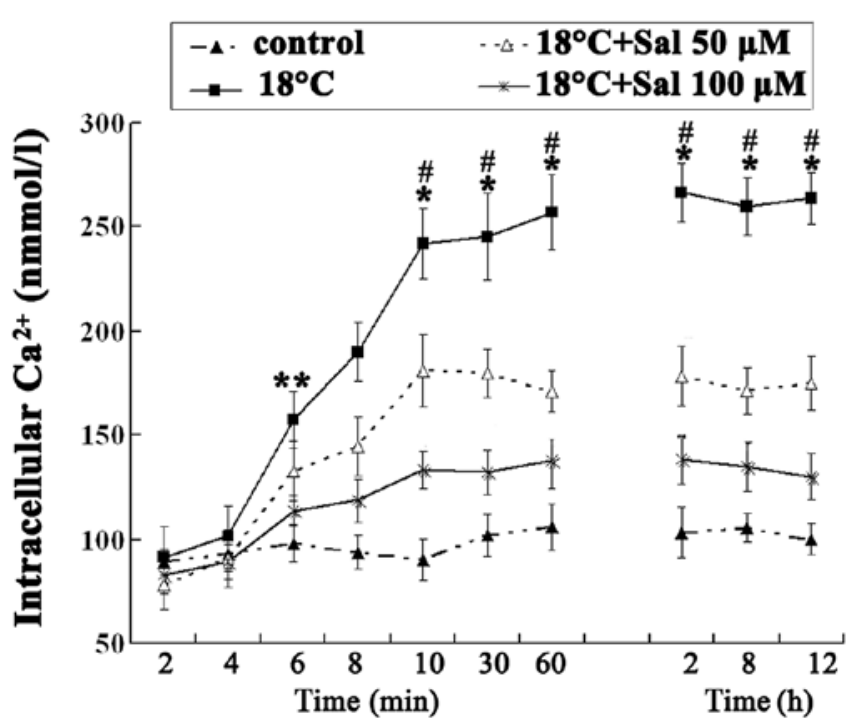

Figure 6. Salidroside attenuates cold-induced increase in intracellular free $\mathrm{Ca}^{2+}\left(\left[\mathrm{Ca}^{2+}\right] \mathrm{i}\right)$ concentration in HBE16 cells. Cells were exposed to cold temperatures $\left(18^{\circ} \mathrm{C}\right)$ for $4 \mathrm{~min}$, at which point the $\left[\mathrm{Ca}^{2+}\right]$ i concentration began to increase. This effect became more significant at 6 min. ${ }^{* * *} \mathrm{P}<0.01$ compared with the control group. Salidroside attenuated the increase in the $\left[\mathrm{Ca}^{2+}\right] \mathrm{i}$ concentration at $10 \mathrm{~min} .{ }^{*} \mathrm{P}<0.05$ compared with the $50 \mu \mathrm{M}$ salidroside-treated group; ${ }^{\#} \mathrm{P}<0.01$ compared with the $100 \mu \mathrm{M}$ salidroside-treated group. Paired Student's t-tests were used to calculate the P-values.

tation. In a previous study, we reported that cold temperatures induce MUC hypersecretion in human airway epithelial cells through a TRPM8-mediated mechanism (12). TRPM8 is a major cold receptor in the body with variants that are expressed by the human respiratory system (19). TRPM 8 is activated by temperatures between 8 and $25^{\circ} \mathrm{C}(20)$ and is a member of the TRP family of $\mathrm{Ca}^{2+}$-permeable, non-selective cation channels and the TRPM subfamily of TRP proteins (21-23). We found that TRPM8 is highly expressed in human airway epithelial cells following exposure to cold stimuli. Functional assays revealed that TRPM8 activation significantly reduced MUC secretion induced by cold temperatures; however, the intervention mechanims for TRPM8-related events have not yet been fully elucidated.

Rhodiola rosea has long been used in traditional Chinese medicine and it primarily grows at high altitude in thin air and cold weather conditions. Salidroside is the major active ingredient isolated from the plant, Rhodiola rosea, and possesses the ability to enhance the resistance of the body to fatigue and cold (24). Salidroside has also been reported to have potent antioxidant and anti-aging properties (25). Salidroside has been shown to reduce $\mathrm{H}_{2} \mathrm{O}_{2}$-induced cell apoptosis in $\mathrm{SH}-\mathrm{SY} 5 \mathrm{Y}$ human neuroblastoma cells $(26,27)$. However, the potential effects of salidroside on cold-induced airway inflammation have not yet been fully elucidated. The respiratory epithelium communicates directly with the external environment. When cold air is inhaled, the respiratory tract loses a considerable amount of heat. This heat loss may be followed by a series of stress reactions. Cold air-induced respiratory symptoms include MUC oversecretion and inflammation, and these phenomena are common in countries or areas with a cold climate (28). It has also been reported that people living at high latitudes exhibit a

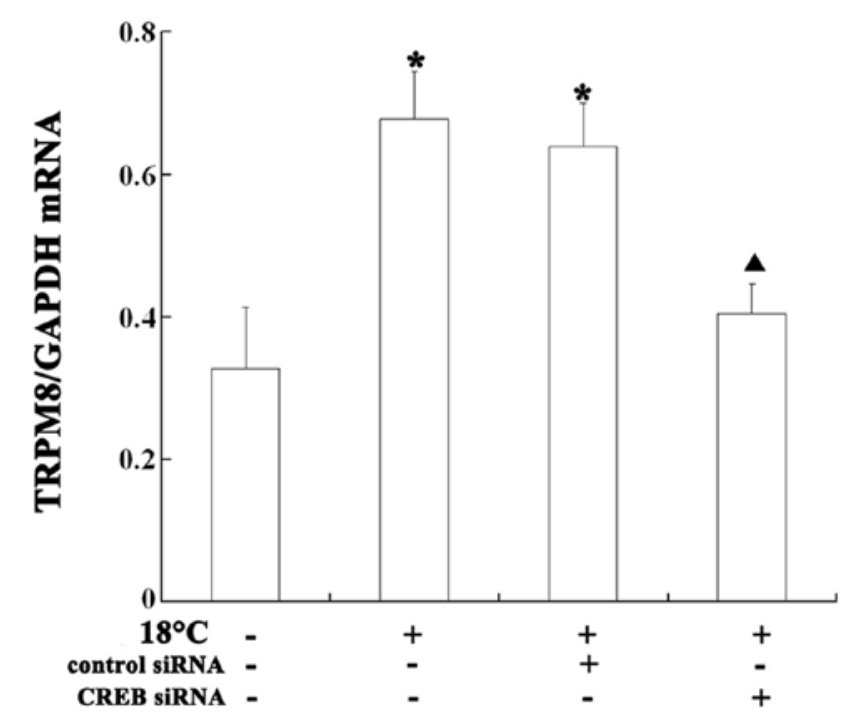

b
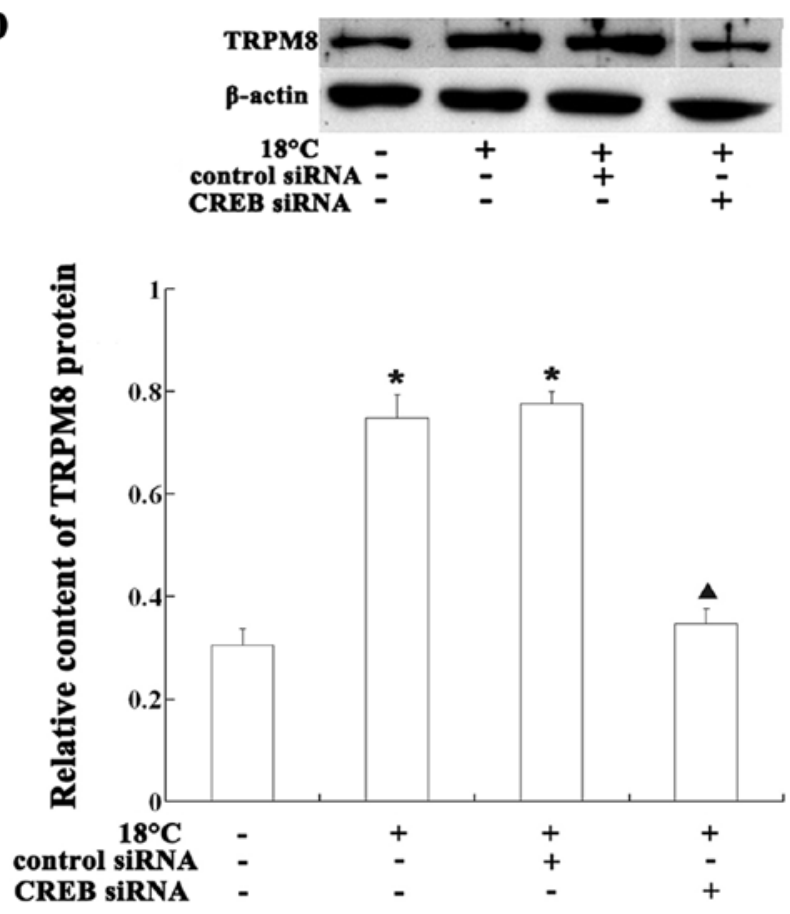

Figure 7. Transfection of cAMP response element-binding protein (CREB) small interfering RNA (siRNA) represses cold-induced transient receptor potential melastatin 8 (TRPM8) expression. HBE16 cells were transfected with CREB siRNA prior to exposure to cold temperatures $\left(18^{\circ} \mathrm{Cl}\right)$. Cells were then cultured for an additional $6 \mathrm{~h}$, at which time TRPM8 mRNA levels were assayed by real-time PCR and protein levels were measured by western blot analysis. (a) TRPM8 mRNA expression following transfection with CREB siRNA. (b) TRPM8 protein expression following transfection with CREB siRNA. " $\mathrm{P}<0.05$ compared with the control group. ${ }^{\wedge} \mathrm{P}<0.01$ compared with the cold-stimulated $\left(18^{\circ} \mathrm{C}\right)$ group. $\mathrm{P}$-values were calculated using the paired Student's t-test. Sal, salidroside.

perturbed mucociliary function, placing them at a higher risk of developing nasal obstruction and cough (29). Considering the known properties of salidroside, we hypothesized that it may play a role in regulating homeostasis in the airway system. 
a
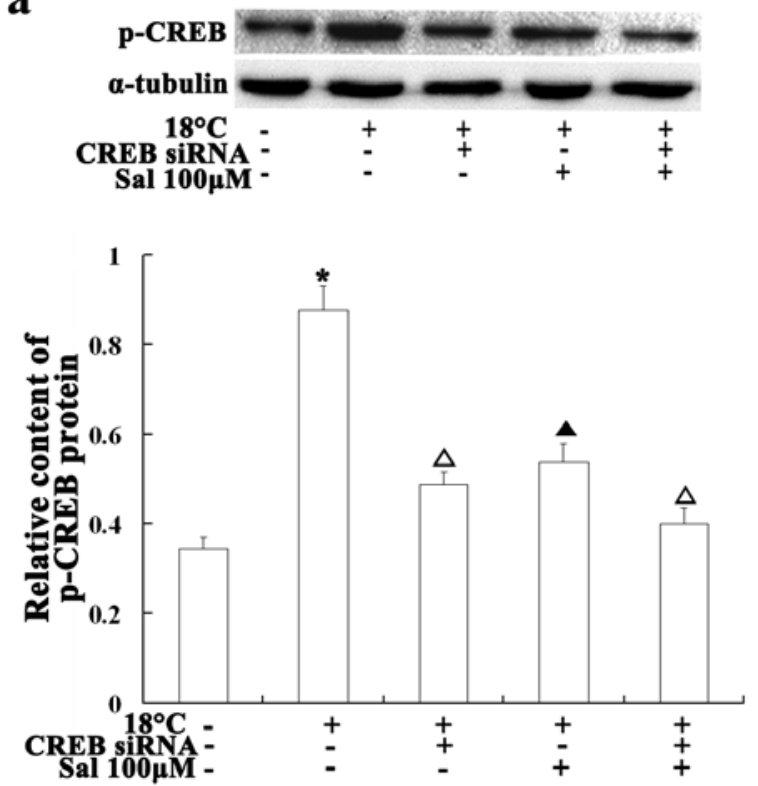

b

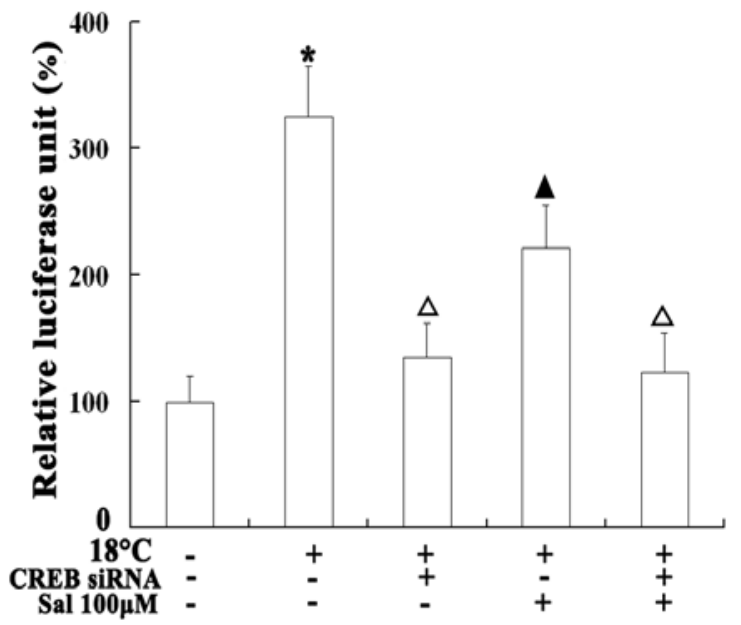

Figure 8. Salidroside reduces cold-induced cAMP response element-binding protein (CREB) phosphorylation and activity. (a) HBE16 cells were cultured in the presence of $100 \mu \mathrm{M}$ salidroside or transfected with CREB small interfering RNA (siRNA) and then exposed to cold temperatures (18 ${ }^{\circ} \mathrm{C}$ ). p-CREB and $\alpha$-tubulin protein levels were measures by western blot analysis. To quantitatively determine p-CREB levels, we performed densitometry analysis for each sample. Protein levels are calculated as the ratio of p-CREB to $\alpha$-tubulin and normalized to the control. Data shown are the means \pm SD from 6 different samples. (b) Cells were transfected with a CREB-Luc Reporter plasmid to measure CREB activity. ${ }^{*} \mathrm{P}<0.05$ compared with the control group; ${ }^{\triangle} \mathrm{P}<0.01$ compared with the coldstimulated $\left(18^{\circ} \mathrm{C}\right)$ group; ${ }^{\wedge} \mathrm{P}<0.05$ compared with the cold-stimulated $\left(18^{\circ} \mathrm{C}\right)$ group. $\mathrm{P}$-values were calculated using the paired Student's t-test. Sal, salidroside.

In this study, we found that HBE16 cells exposed to cold temperatures exhibited a marked increase in MUC5AC levels and TRPM8 activation. By contrast, cells pre-treated with various concentrations of salidroside $(10,50$ and $100 \mu \mathrm{M})$ prior to the cold assault exhibited a dose- and time-dependent decrease in MUC5AC expression, indicating that salidroside is capable of protecting HBE16 cells from cold-induced MUC oversecretion. Furthermore, we found that the $\left[\mathrm{Ca}^{2+}\right] \mathrm{i}$ concentration rapidly and robustly increased in the cold-stimulated cells, reaching a plateau at 6 to $10 \mathrm{~min}$ following exposure to cold temperatures. The cells pre-treated with salidroside showed decreased levels of $\left[\mathrm{Ca}^{2+}\right] \mathrm{i}$ and TRPM8 activation, with the $\left[\mathrm{Ca}^{2+}\right]$ i concentration decreasing as early as $1 \mathrm{~min}$ following incubation with salidroside and reaching a minimal level at $2 \mathrm{~h}$ post-treatment. High doses of salidroside inhibited the inflow of $\mathrm{Ca}^{2+}$ almost completely.

$\left[\mathrm{Ca}^{2+}\right] \mathrm{i}$ is an important second messenger in various types of cells, regulating functional and physiological cellular activities, such as contraction, secretion, signal transmission and transcriptional regulation. Under normal circumstances, the extracellular concentration of calcium is usually $0.1-10 \mathrm{mM}$ and the intracellular calcium concentration is $10^{-7}-10^{-8} \mathrm{M}$, much lower than the calcium concentrations in the extracellular environment. $\mathrm{Ca}^{2+}$-dependent cellular signaling pathways are activated by alterations in the levels of $\left[\mathrm{Ca}^{2+}\right]$ i. When cells are exposed to stimuli such as inflammation (30), hypoxia (31) and cold temperatures (32), there is an influx of extracellular calcium or a release of calcium from the cellular endoplasmic reticulum, either of which overloads the $\left[\mathrm{Ca}^{2+}\right] \mathrm{i}$ level. The $\left[\mathrm{Ca}^{2+}\right]$ i concentration plays an important role in the activation of TRPM8. Studies have also shown that TRPM8 mediates transmembrane $\mathrm{Ca}^{2+}$ flux (33). However, the excessive inflow of $\mathrm{Ca}^{2+}$ leads to desensitization of TRPM8, a process that is mediated through the $\mathrm{Ca}^{2+}$-dependent activation of protein kinase C (PKC) $(34,35)$. TRPM8 is also regulated by a number of kinases and second messengers, such as PLC, PIP2 $(36,37)$, phospholipase A2 (PLA2), lysophospholipids (LPLs) $(38,39)$, arachidonic acid (AA) (40) and cAMP (41).

CREB is a $43-\mathrm{kDa}$ leucine zipper transcription factor that belongs to the activating transcription factor (ATF) subfamily of the basic-region leucine zipper (bZIP) family. CREB primarily responds to the cAMP signaling pathway, binding to CREs to increase or decrease the transcription of certain genes (42). CREB-mediated transcription regulates various cellular responses, including intermediary metabolism, neuronal signaling, cell proliferation, apoptosis and other molecular events. The CREB protein contains an $\mathrm{N}$-terminal transaction domain (kinase-induced domain), a basic region and a leucine zipper motif at the $\mathrm{C}$-terminus. The transaction domain includes a phosphorylation site at Ser133 that is recognized by certain protein kinases (43). CREB can be activated by a variety of stimuli, including peptide hormones, growth factors, forskolin, phorbol esters and a number of protein kinases, including protein kinase A (PKA), pp90 ribosomal S6 kinase (pp90RSK), and $\mathrm{Ca}^{2+} /$ calmodulin-dependent protein kinases (CaMKs) $(44,45)$.

It has been reported that the TRPM8 core promoter region contains a CRE, which is possibly located between base pairs $-1,417$ and $-1,406$. It may play an important role in promoting the transcription of TRPM8 $(18,46)$. Therefore, we further examine whether the transcription factor, CREB, is involved in TRPM8 expression. We found that the expression of p-CREB protein and CREB activity were significantly elevated in the cells exposed to cold temperatures compared 
with the control cells. CREB phosphorylation and activity levels were lower in the cells pre-treated with salidroside than the untreated cells. While TRPM8 expression decreased in the cells transfected with CREB siRNA, the expression of TRPM8 in the cells transfected with CREB siRNA and incubated with salidroside prior to exposure to cold temperatures decreased even more significantly. These results indicate not only that CREB activation directly contributes to TRPM8 expression, but also that salidroside inhibits TRPM8 expression by decreasing the activation and activity of CREB.

The known chemical antagonists of TRPM8 are capsazepine, N-(4-tert-butylphenyl)-4-(3-chloropyridin-2-yl) tetrahydropyrazine-1 $(2 \mathrm{H})$-carboxamite (BCTC) and thiol BCTC. While these are all synthesized chemicals, salidroside is a component of the Chinese herb, Rhodiola rosea, which may be a natural candidate for the treatment of diseases involving TRPM8 overexpression. The regulation of TRPM8 expression by salidroside is important for the identification of alternative treatment modalities for airway mucus hypersecretory diseases induced by cold stimuli.

\section{Acknowledgements}

The present study was supported by the National Nature Science Foundation of China (grant no. 81100003 and 31171346), and the China-Russia Cooperation Research Foundation (grant no. 31211120168), and the New Teacher Fund for Doctor Station, the Ministry of Education, China (no. 20115503120006), and Chongqing Nature Science Foundation (grant no. cstc2011jjA10046).

\section{References}

1. Giesbrecht GG: The respiratory system in a cold environment. Aviat Space Environ Med 66: 890-902, 1995.

2. Voynow JA and Rubin BK: Mucins, mucus, and sputum. Chest 135: 505-512, 2009.

3. Zhen G, Park SW, Nguyenvu LT, Rodriguez MW, Barbeau R, Paquet AC and Erle DJ: IL-13 and epidermal growth factor receptor have critical but distinct roles in epithelial cell mucin production. Am J Respir Cell Mol Biol 36: 244-253, 2007.

4. Zhu L, Lee PK, Lee WM, Zhao Y, Yu D and Chen Y: Rhinovirus-induced major airway mucin production involves a novel TLR3-EGFR-dependent pathway. Am J Respir Cell Mol Biol 40: 610-619, 2009.

5. Turner $\mathbf{J}$ and Jones CE: Regulation of mucin expression in respiratory diseases. Biochem Soc Trans 37: 877-881, 2009.

6. Caterina MJ, Leffler A, Malmberg AB, Martin WJ, Trafton J, Petersen-Zeitz KR, Koltzenburg M, Basbaum AI and Julius D: Impaired nociception and pain sensation in mice lacking the capsaicin receptor. Science 288: 306-313, 2000.

7. Caterina MJ, Rosen TA, Tominaga M, Brake AJ and Julius D: A capsaicin-receptor homologue with a high threshold for noxious heat. Nature 398: 436-441, 1999.

8. Smith GD, Gunthorpe MJ, Kelsell RE, Hayes PD, Reilly P, Facer P, Wright JE, Jerman JC, Walhin JP, Ooi L, Egerton J, Charles KJ, Smart D, Randall AD, Anand P and Davis JB: TRPV3 is a temperature-sensitive vanilloid receptor-like protein. Nature 418: 186-190, 2002.

9. Güler AD, Lee H, Iida T, Shimizu I, Tominaga M and Caterina M: Heat-evoked activation of the ion channel, TRPV4. J Neurosci 2: 6408-6414, 2002.

10. McKemy DD, Neuhausser WM and Julius D: Identification of a cold receptor reveals a general role for TRP channels in thermosensation. Nature 416: 52-58, 2002.

11. Peier AM, Moqrich A, Hergarden AC, Reeve AJ, Andersson DA, Story GM, Earley TJ, Dragoni I, McIntyre P, Bevan S and Patapoutian A: A TRP channel that senses cold stimuli and menthol. Cell 108: 705-715, 2002.
12. Li MC, Li Q, Yang G, Kolosov VP, Perelman JM and Zhou XD: Cold temperature induces mucin hypersecretion from normal human bronchial epithelial cells in vitro through a transient receptor potential melastatin 8 (TRPM8)-mediated mechanism. J Allergy Clin Immunol 128: 626-634, 2011.

13. Li YR, Cao W, Guo J, Miao S, Ding GR, Li KC, Wang J and Guo GZ: Comparative investigations on the protective effects of rhodioside, ciwujianoside-B and astragaloside IV on radiation injuries of the hematopoietic system in mice. Phytother Res 25: 644-653, 2011.

14. Díaz Lanza AM, Abad Martínez MJ, Fernández Matellano L, Recuero Carretero C, Villaescusa Castillo L, Silván Sen AM and Bermejo Benito P: Lignan and phenylpropanoid glycosides from Phillyrea latifolia and their in vitro anti inflammatory activity. Planta Med 67: 219-223, 2001.

15. Kelly GS: Rhodiola rosea: a possible plant adaptogen. Altern Med Rev 6: 293-302, 2001.

16. Kucinskaite A, Briedis V and Savickas A: Experimental analysis of therapeutic properties of Rhodiola rosea $L$. and its possible application in medicine. Medicina (Kaunas) 40: 614-619, 2004 (In Lithuanian).

17. Bavencoffe A, Kondratskyi A, Gkika D, Mauroy B, Shuba Y, Prevarskaya N and Skryma R: Complex regulation of the TRPM8 cold receptor channel: role of arachidonic acid release following M3 muscarinic receptor stimulation. J Biol Chem 286: 9849-9855, 2011.

18. Bidaux G, Roudbaraki M, Merle C, Crépin A, Delcourt P, Slomianny C, Thebault S, Bonnal JL, Benahmed M, Cabon F, Mauroy B and Prevarskaya N: Evidence for specific TRPM8 expression in human prostate secretory epithelial cells: functional androgen receptor requirement. Endocr Relat Cancer 12: 367-382, 2005.

19. Sabnis AS, Shadid M, Yost GS and Reilly CA: Human lung epithelial cells express a functional cold-sensing TRPM8 variant. Am J Respir Cell Mol Biol 39: 466-474, 2008.

20. McCoy DD, Knowlton WM and McKemy DD: Scraping through the ice: uncovering the role of TRPM8 in cold transduction. Am J Physiol Regul Integr Comp Physiol 300: R1278-R1287, 2011.

21. Zhang L and Barritt GJ: TRPM8 in prostate cancer cells: a potential diagnostic and prognostic marker with a secretory function? Endocr Relat Cancer 13: 27-38, 2006.

22. Behrendt HJ, Germann T, Gillen C, Hatt H and Jostock R: Characterization of the mouse cold-menthol receptor TRPM8 and vanilloid receptor type-1 VR1 using a fluorometric imaging plate reader (FLIPR) assay. Br J Pharmacol 141: 737-745, 2004

23. Andersson DA, Chase HW and Bevan S: TRPM8 activation by menthol, icilin, and cold is differentially modulated by intracellular pH. J Neurosci 24: 5364-5369, 2004.

24. Tolonen A, Pakonen M,Hohtola A and Jalonen J: Phenylpropanoid glycosides from Rhodiola rosea. Chem Pharm Bull (Tokyo) 51: 467-470, 2003.

25. Mao GX, Wang Y, Qiu Q, Deng HB, Yuan LG, Li RG, Song DQ, Li YY, Li DD and Wang Z: Salidroside protects human fibroblast cells from premature senescence induced by $\mathrm{H}(2) \mathrm{O}(2)$ partly through modulating oxidative status. Mech Ageing Dev 131: 723-731, 2010.

26. Li X, Ye X, Li X, Sun X, Liang Q, Tao L, Kang X and Chen J: Salidroside protects against MPP(+)-induced apoptosis in PC12 cells by inhibiting the NO pathway. Brain Res 1382: 9-18, 2011.

27. Zhang L, Yu H, Sun Y, Lin X, Chen B, Tan C, Cao G and Wang Z: Protective effects of salidroside on hydrogen peroxide-induced apoptosis in SH-SY5Y human neuroblastoma cells. Eur J Pharmacol 564: 18-25, 2007.

28. Koskela HO: Cold air-provoked respiratory symptoms: the mechanisms and management. Int J Circumpolar Health 66: 91-100, 2007.

29. Rodway GW and Windsor JS: Airway mucociliary function at high altitude. Wilderness Environ Med 17: 271-275, 2006.

30. Dada LA and Sznajder JI: Mitochondrial $\mathrm{Ca}^{2+}$ and ROS take center stage to orchestrate $\mathrm{TNF}-\alpha$-mediated inflammatory responses. J Clin Invest 121: 1683-1685, 2011.

31. Gusarova GA, Trejo HE, Dada LA, Briva A, Welch LC, Hamanaka RB, Mutlu GM, Chandel NS, Prakriya M and Sznajder JI: Hypoxia leads to Na,K-ATPase downregulation via $\mathrm{Ca}(2+)$ release-activated $\mathrm{Ca}(2+)$ channels and AMPK activation. Mol Cell Biol 31: 3546-3556, 2011.

32. Galli GL, Lipnick MS, Shiels HA and Block BA: Temperature effects on $\mathrm{Ca}^{2+}$ cycling in scombrid cardiomyocytes: a phylogenetic comparison. J Exp Biol 214: 1068-1076, 2011. 
33. Cho Y, Jang Y, Yang YD, Lee CH, Lee Y and Oh U: TRPM 8 mediates cold and menthol allergies associated with mast cell activation. Cell Calcium 48: 202-208, 2010

34. Abe J, Hosokawa H, Sawada Y, Matsumura K and Kobayashi S: $\mathrm{Ca}^{2+}$-dependent PKC activation mediates menthol-induced desensitization of transient receptor potential M8. Neurosci Lett 397: 140-144, 2006.

35. Premkumar LS, Raisinghani M, Pingle SC, Long C and Pimentel F: Downregulation of transient receptor potential melastatin 8 by protein kinase $\mathrm{C}$-mediated dephosphorylation. $\mathrm{J}$ Neurosci 25: 11322-11329, 2005.

36. Daniels RL, Takashima Y and McKemy DD: Activity of the neuronal cold sensor TRPM8 is regulated by phospholipase $C$ via the phospholipid phosphoinositol 4,5-bisphosphate. J Biol Chem 84: 1570-1582, 2009.

37. Rohács T, Lopes CM, Michailidis I and Logothetis DE: PI(4,5)P2 regulates the activation and desensitization of TRPM8 channels through the TRP domain. Nat Neurosci 8: 626-634, 2005.

38. Andersson DA, Nash M and Bevan S: Modulation of the cold-activated channel TRPM8 by lysophospholipids and polyunsaturated fatty acids. J Neurosci 27: 3347-3355, 2007.

39. Vanden Abeele F, Zholos A, Bidaux G, Shuba Y, Thebault S, Beck B, Flourakis M, Panchin Y, Skryma R and Prevarskaya N: $\mathrm{Ca}^{2+}$-independent phospholipase A2-dependent gating of TRPM8 by lysophospholipids. J Biol Chem 281: 40174-40182, 2006.
40. Bavencoffe A, Gkika D, Kondratskyi A, Beck B, Borowiec AS, Bidaux G, Busserolles J, Eschalier A, Shuba Y, Skryma R and Prevarskaya N: The transient receptor potential channel TRPM8 is inhibited via the alpha $2 \mathrm{~A}$ adrenoreceptor signaling pathway. $\mathrm{J}$ Biol Chem 285: 9410-9419, 2010.

41. De Petrocellis L, Starowicz K, Moriello AS, Vivese M, Orlando P and Di Marzo V: Regulation of transient receptor potential channels of melastatin type 8 (TRPM8): effect of cAMP, cannabinoid CB(1) receptors and endovanilloids. Exp Cell Res 313: 1911-1920, 2007.

42. Andrisani OM: CREB-mediated transcriptional control. Crit Rev Eukaryot Gene Expr 9: 19-32, 1999.

43. Johannessen M and Moens U: Multisite phosphorylation of the cAMP response element-binding protein (CREB) by a diversity of protein kinases. Front Biosci 12: 1814-1832, 2007.

44. Johannessen M, Delghandi MP, Seternes OM, Johansen B and Moens U: Synergistic activation of CREB-mediated transcription by forskolin and phorbol ester requires PKC and depends on the glutamine-rich Q2 transactivation domain. Cell Signal 16: $1187-1199,2004$

45. Shaywitz AJ and Greenberg ME: CREB: a stimulus-induced transcription factor activated by a diverse array of extracellular signals. Annu Rev Biochem 68: 821-861, 1999.

46. Zhang L and Barritt GJ: Evidence that TRPM8 is an androgen-dependent $\mathrm{Ca}^{2+}$ channel required for the survival of prostate cancer cells. Cancer Res 64: 8365-8373, 2004. 